\title{
A 20-year record of water chemistry in an alpine setting, Mount Emmons, Colorado, USA
}

\author{
Richard B. Wanty ${ }^{1, *}$, Andrew H. Manning ${ }^{2}$, Michaela R. Johnson ${ }^{2}$, Philip L. Verplanck ${ }^{2}$ \\ ${ }^{1}$ U.S. Geological Survey, MS 963 Denver Federal Center, Denver, CO 80225 USA \\ ${ }^{2}$ U.S. Geological Survey, MS 973 Denver Federal Center, Denver, CO 80225 USA
}

\begin{abstract}
From 1997 to the present, the U.S. Geological Survey and other agencies have been collecting water samples for chemical analyses on Mount Emmons in central Colorado, USA. The geology of Mount Emmons is dominated by Upper Cretaceous to Paleogene sediments of marine to continental origin, with felsic intrusive rocks interrupting the sedimentary block. Extensive sulphide-rich alteration accompanied the intrusive events and forms an alteration halo in the sediments. Weathering of these sulphide minerals has led to numerous springs and seeps with a naturally low $\mathrm{pH}$ and high concentrations of metals, especially $\mathrm{Fe}$ and $\mathrm{Zn}$. Superimposed on the natural geochemical signature are acid, metal-rich drainages from several mines and drill holes. Thus, streams on Mt. Emmons have a mix of natural and anthropogenic metal sources. Nearly 450 samples compose the database, with numerous sample locations replicated from the late 1990s to the present. Although there does not appear to be any temporal pattern in the data, consistent spatial variations are observed that allow us to characterize the natural and anthropogenic water sources.
\end{abstract}

\section{Introduction}

In previous papers [1-3], we have reported on the chemistry of waters on Mount Emmons in central Colorado, USA (Fig. 1). The Redwell Basin on the north flank of Mount Emmons is particularly interesting because of its naturally acid springs and manmade features such as acid mine drainage. Our previous efforts have focused on resolving natural and anthropogenic inputs, but a new compilation of data spanning 20 years gathered by our U.S. Geological Survey (USGS) group and by other agencies working in the area allows for the examination of temporal trends in the data. One testable hypothesis is whether any temporal trends in water chemistry can be attributed to recent climate warming [4]. An application of the data derives from an earlier (2013) remediation of one of the anthropogenic sources of acid, metal-rich water, and the effect that remediation may have had on overall streamwater quality.

\footnotetext{
* Corresponding author: rwanty@usgs.gov
} 
Mount Emmons comprises a thick, high-relief sequence of sediments ranging from Cretaceous to Tertiary age, with several younger felsic intrusive rocks [5]. The intrusive rocks caused extensive hydrothermal alteration of the sediments, adding abundant sulphide minerals such as pyrite, sphalerite, and galena, primarily in veins. Numerous mines and prospects are scattered around the mountain, especially in the Redwell, Elk, and Peeler basins. Mount Emmons is an alpine environment, with steep slopes and thin to no soil cover. Average temperature is approximately $4{ }^{\circ} \mathrm{C}$. Precipitation mainly falls as snow from September to May in typical years, with rainy periods in the summer and an average annual total of about $70 \mathrm{~cm}$.

\section{Results}

\subsection{Data quality- combining multiple sources of data}

The first challenge in combining large datasets is to evaluate the quality of the data derived from each source and whether the multiple datasets are directly comparable. The former can be evaluated through the calculation of charge balance, by direct comparison of multiple analyses of the same element by different methods, and by evaluating the reproducibility of duplicate samples collected in the field. Comparing datasets from multiple sources is mostly evaluated through comparison of repeated samples from uniquely identifiable locations and from distributions within each dataset.

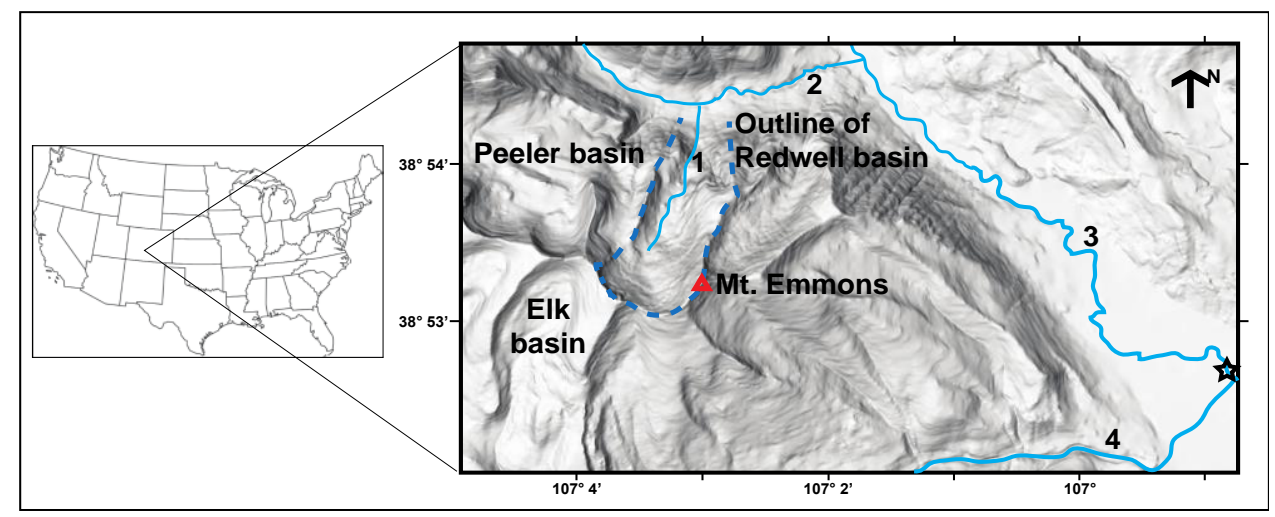

Fig. 1. Base map of Mount Emmons study area. $1=$ Redwell Creek, 2 = Oh-be-joyful Creek, $3=$ Slate River, 4 = Coal Creek. Summit of Mount Emmons is $3770 \mathrm{~m}$ a.s.1.; confluence of Redwell Creek with Oh-be-joyful Creek is $2865 \mathrm{~m}$ a.s.l. 2300 meters distant (average gradient $=0.39$ ).
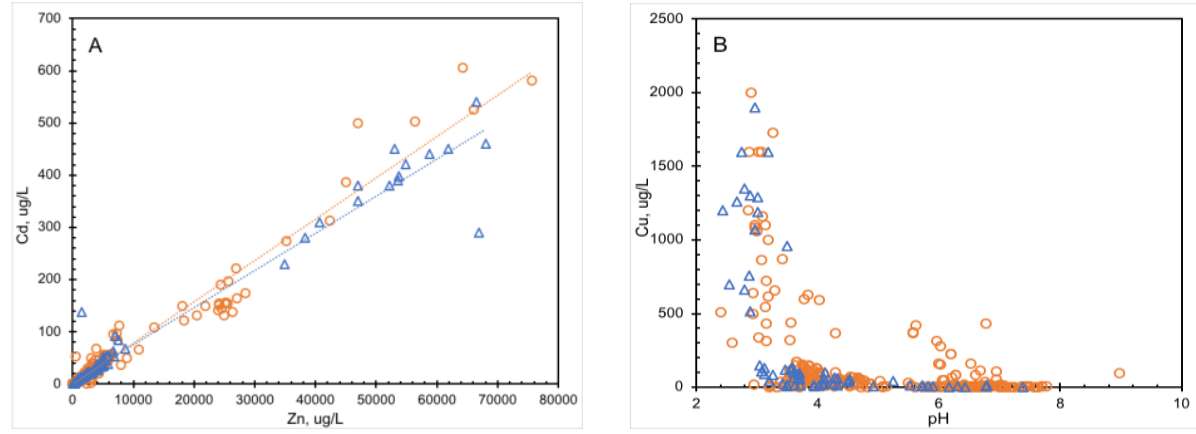

Fig. 2. (A) Zn and Cd data for water samples collected by USGS (orange circles) and by other agencies (blue triangles). (B) $\mathrm{Cu}$ and $\mathrm{pH}$ for USGS and other agency data (same symbols). 

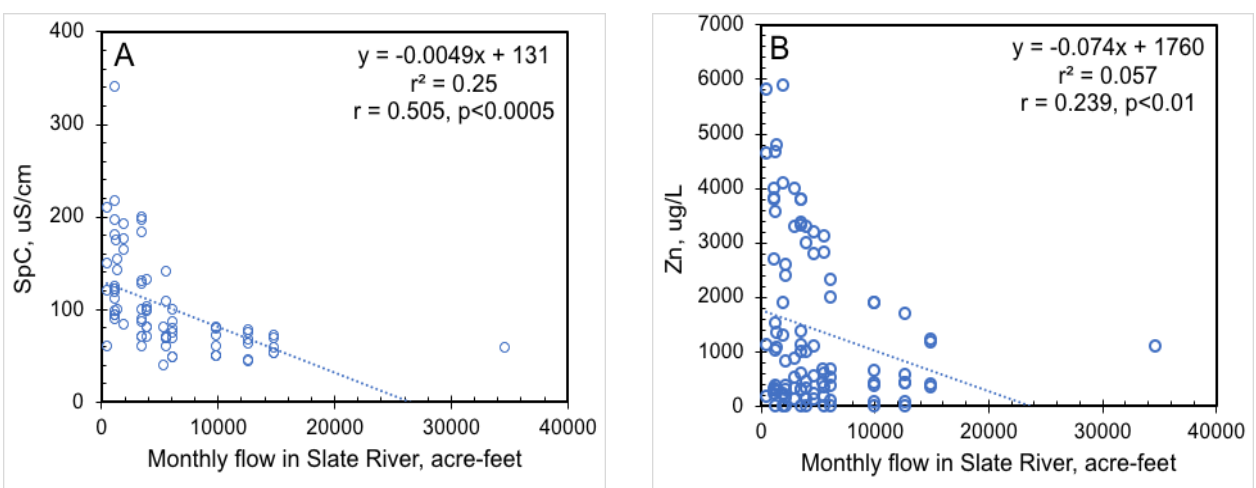

Fig. 3. (A) Specific conductance of Redwell Creek versus monthly discharge in the Slate River. (B) $\mathrm{Zn}$ versus monthly discharge, same locations. Linear best-fit parameters in top right of each figure. Data from USGS and other agencies combined into one dataset for the purpose of calculating correlations. (1 acre-foot is equivalent to $1233 \mathrm{~m}^{3}$ ).

Charge balances were calculated for USGS-derived samples, as well as samples from other sources for which complete chemical analyses existed [6]. In most cases, the nonUSGS analyses were incomplete, preventing a charge-balance calculation. For these analyses, we are mostly limited to comparing USGS datasets with the outside data. Figure $2 \mathrm{~A}$ shows a direct comparison of $\mathrm{Zn}$ and $\mathrm{Cd}$ data for the USGS versus other data. The $\mathrm{Zn} / \mathrm{Cd}$ molar ratio for the USGS data is 218 ; that for the other data is 242 . If the low outlier point (at 67000, 290) in the non-USGS data is removed from the calculation, the $\mathrm{Zn} / \mathrm{Cd}$ ratio is 229 . The two datasets are similar; thus, it is possible to make direct comparisons between the two. Similar results are obtained for comparisons of other dissolved constituents, including $\mathrm{pH}, \mathrm{SO}_{4}{ }^{2-}, \mathrm{Cu}$, and $\mathrm{Pb}$. Figure $2 \mathrm{~B}$ shows the distribution of dissolved $\mathrm{Cu}$ concentrations vs. $\mathrm{pH}$. As with the $\mathrm{Zn}: \mathrm{Cd}$ data, the two populations overlap completely.

\subsection{Links to hydrologic data}

Previous authors $[7,8]$ found a steady increase in the concentrations of dissolved metals and sulphate in the upper Snake River in the Colorado Front Range (125 km distant) from 1980 to 2012. They attributed these increases to a falling water table, caused by declining recharge rates due to recent climate changes. The Snake River is hydrothermally altered and mineralized, similar to Mount Emmons, but its geology is dominated by fractured crystalline metamorphic rocks, in contrast to the sedimentary edifice of Mount Emmons. Nevertheless, it would be desirable to test if similar climatic effects are evident in the Mount Emmons area. Lacking water table elevation data as reported in Manning et al. [8], we use hydrologic data in the form of cumulative stream discharge [9]. Discharge is reported for the Slate River at the location marked by the star on the right edge of Figure 1, in annual and monthly totals. Within each year there are seasonal variations, but there is no consistent interannual trend in discharge from 1997 to the present. When chemical data are plotted against annual cumulative discharge, there is no correlation. However, when chemical analyses are compared to the monthly discharge totals from the same month, correlations emerge (Fig.3). For all constituents tested, there is a negative correlation between concentration and monthly discharge, as would be expected if a higher flow dilutes the concentrations of chemical constituents. For most constituents, correlations are significant at $>99 \%$ confidence, except for $\mathrm{Pb}$, which was significant at $95 \%$. Values of $\mathrm{r}^{2}$, roughly a measure of the proportion of the variance in concentration that is explained by 
changes in discharge, vary from 0.03 to 0.3 ; so even though the correlations are significant, changes in discharge account for less than a third of the chemical variations.

\subsection{Temporal variations}

When considering variations in chemistry versus time, some patterns emerge. Prior to November 2013, an exploration well with artesian flow was present near the top of the Redwell Basin. The water emanating from the well had low $\mathrm{pH}(<3.0)$ and high concentrations of Zn (2500-7300 $\mu \mathrm{g} / \mathrm{L})$ and other metals. In November 2013, the well was plugged in an effort to decrease metal loads contributed by Redwell Creek to Oh-be-joyful Creek. The time at which the well was plugged is shown by the vertical arrows in Figure 4. Zinc concentrations in upper Redwell Creek remained below $\sim 500 \mu \mathrm{g} / \mathrm{L}$ after plugging (Fig. 4A). But in lower Redwell Creek, just above its confluence with Oh-be-joyful Creek (Fig.4B), there is a considerable range of scatter in $\mathrm{Zn}$ concentrations, but no temporal trend, and no obvious decrease in $\mathrm{Zn}$ concentrations after plugging the artesian well. A likely reason for the lack of improvement is that the abundance of metals contributed by the artesian well was small relative to other sources, such as the discharge from the Daisy Mine and the Red Well natural spring [3]. In Figure 4A, Zn concentrations are up to 1300 $\mu \mathrm{g} / \mathrm{L}$ prior to plugging, but in Figure 4B, Zn ranges from 1000 to almost $5000 \mu \mathrm{g} / \mathrm{L}$ due to the added $\mathrm{Zn}$ from the Daisy Mine and the Red Well spring. In Oh-be-joyful Creek, Zn concentrations are low $(<15 \mu \mathrm{g} / \mathrm{L})$ upstream from the confluence with Redwell Creek but increase to mostly $>100 \mu \mathrm{g} / \mathrm{L}$ downstream. This concentration of $\mathrm{Zn}$ is great enough to cause adverse effects to aquatic organisms [10].

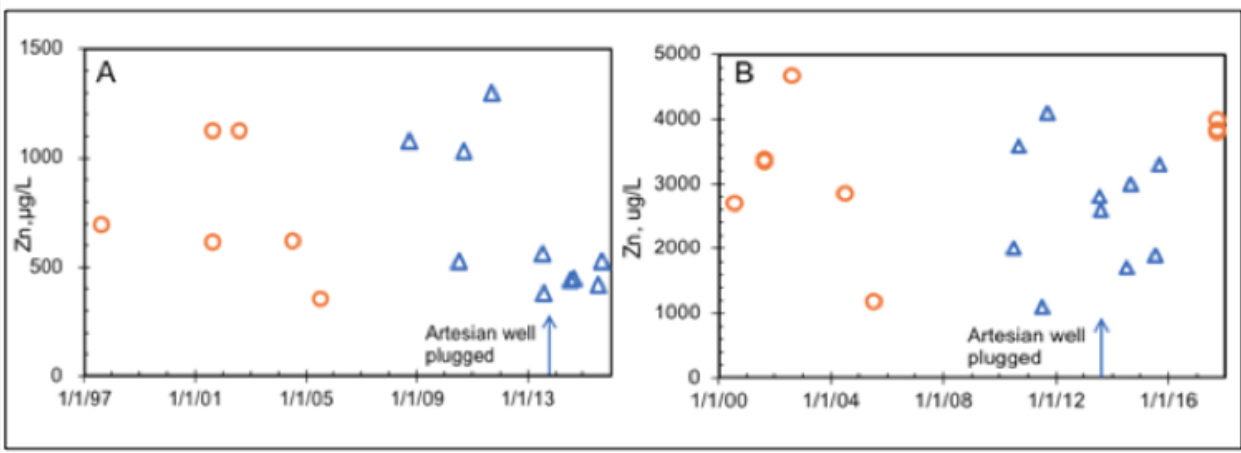

Fig. 4. (A) Concentration of Zn versus time in Redwell Creek upstream from the confluence with the Red Well spring, but downstream from the artesian well (see text). (B) Concentration of Zn vs. time in Redwell Creek just above its confluence with Oh-be-joyful Creek. USGS data (orange circles) and other agency data (blue triangles).

The dataset also includes temporally dense sampling of groundwater from the Red Well spring, and drainage from the Daisy Mine. There is some temporal and seasonal scatter in the data for each, but there is no clear long-term trend in metals or sulphate concentrations. Unlike for the surface waters described above, no correlations exist between dissolved constituent concentrations and surface-water discharge. A likely reason for this lack of correlation is the greater subsurface residence time for these emerging groundwaters compared to stream water.

Long-term trends in metal concentrations that have been observed in the upper Snake River basin in Colorado have been attributed to climate changes and falling water tables [8], which exposes previously pristine sulphide minerals to an oxidizing weathering 
environment. One possible explanation for a lack of an observed similar trend in Redwell Basin is that recently installed boreholes suggest that the active fractured-rock aquifer high in the basin is considerably shallower and thinner and contains less pyrite to become exposed when the water table falls. Therefore, at Mount Emmons, the lack of a temporal trend may be due to hydrogeologic differences rather than climatic ones.

\section{Summary}

A long-term record of water chemistry from Mount Emmons, central Colorado, USA, reveals correlations to climate data, but no long-term trends, as have been observed elsewhere. The lack of long-term trends is likely due to hydrogeologic differences between Mount Emmons and other areas where long-term trends have been observed. An attempt at remediation of an artesian well that supplied metals and sulphate to Redwell Creek appears to have decreased metal concentrations in upper Redwell Creek, proximal to the inflow from the well. However, due to larger metal sources entering Redwell Creek farther downstream, the overall effect of the remediation of the artesian well is negligible. Using long-term datasets such as the one described here can provide valuable insights into geochemical and hydrologic processes taking place in alpine watersheds, provided that proper care is taken to assure data quality and compatibility between datasets originating from different sources.

This work was funded by the U.S. Geological Survey Mineral Resources Program and the U.S. Department of Energy Subsurface Biogeochemical Research Program.

\section{References}

1. P.L. Verplanck, et al., in Wanty, R.B., and Seal, R.R. II, eds., Proc. $11^{\text {th }}$ Int. Symp. Water-Rock Interaction: Taylor and Francis, London, pp. 1649-1653 (2004)

2. R.B. Wanty, et al., in Wanty, R.B., and Seal, R.R. II, eds., Proc. $11^{\text {th }}$ Int. Symp. Water-Rock Interaction: Taylor and Francis, London, pp. 1659-1663 (2004)

3. B.A. Kimball, et al., Chem Geol 269, 124-136 (2010)

4. Clow, D.W., J Clim, 23, 2293-2306 (2010)

5. D.L. Gaskill, et al., US Geol Surv Geol Quad Map GQ-578 (1967)

6. D. Parkhurst, C.A.J. Appelo, US Geol Surv Water Resour Inv Rpt. 99-4259 (1999)

7. A.S. Todd, et al., Env Sci Technol 46, 9324-9332 (2012)

8. A.H. Manning, et al., Appl Geochem, 37, 64-78 (2013)

9. U.S. Dept. Agriculture, Natural Resources Conservation Service. Website accessed November 2018. [https://www.wcc.nrcs.usda.gov/index.html]

10. T.S. Schmidt, et al., Env Sci Technol, 47, 8783-8792 (2013) 